\title{
Cytokines and clustered cardiovascular risk factors in children
}

\section{Running title: Cytokines and metabolic syndrome}

Lars Bo Andersen, DMSc. ${ }^{1,2}$, Klaus Müller, DMSc. ${ }^{3}$, Stig Eiberg, Ph.D. , Karsten

Froberg $^{1}$, Johnny Fredsbo Børm Andersen, M.D. ${ }^{5}$, Anna Bugge, M.Sc. ${ }^{1}$, Bianca El-

Naaman Hermansen, M.Sc. ${ }^{1}$, Robert G McMurray, Ph.D. ${ }^{6}$.

${ }^{1}$ Institute of Sport Science and Clinical Biomechanics, University of Southern Denmark,

Denmark.

${ }^{2}$ Norwegian School of Sport Sciences, Oslo, Norway.

${ }^{3}$ Rigshospitalet Paediatric Clinic II, Copenhagen, Denmark

${ }^{4}$ Team Denmark, Copenhagen, Denmark

${ }^{5}$ Rigshospitalet, Institute of Inflammation Research, Copenhagen, Denmark

${ }^{6}$ University of North Carolina, Department of Exercise and Sport Science, North Carolina, USA

Corresponding author:

Lars Bo Andersen, prof. PhD, Dr Med Sci

Institute of Sport Science and Clinical Biomechanics

Campusvej 55, Odense DK-5230, Denmark

Mail: 1boandersen@health.sdu.dk

Phone: +4565504380

Fax: +4565503480 


\section{Abstract}

The aim was to evaluate the possible role of tumor necrosis factor $\alpha$ (TNF- $\alpha$ ), interleukin6 (IL-6), C-reactive protein (CRP), low fitness and fatness in the early development of clustering of cardiovascular disease (CVD) risk factors and insulin resistance (IR). Subjects for this cross-sectional study were obtained from 18 schools near Copenhagen, DK. Two hundred and ten, 9-year-old children were selected for cytokine analysis from 434 third grade children with complete CVD risk profiles. The subgroup was selected according to their CVD risk factor profile (upper and lower quartile of a composite CVD risk score). All the CVD risk factors and CRP differed between the high and low risk groups, but plasma glucose, TNF- $\alpha$, and IL-6 had small and inconsistent differences. Strong associations were found between CVD risk scores and fitness $\left(\mathrm{VO}_{2 \text { peak }}\right)$ or fatness. No associations were found between CVD risk scores and TNF- $\alpha$ and IL-6. CRP was associated with fitness, fatness, and CVD risk score. This study does not support an association between plasma IL-6 or TNF- $\alpha$ and low insulin sensitivity or clustering of CVD risk factors in a young cohort. Inflammation was more pronounced in fat and unfit children based on the association with CRP levels. The association between fitness and fatness variables, insulin resistance and clustered risk could be caused by other mechanisms related to these exposures. The role of IL-6 remains unclear. Keywords: syndrome X; exercise; obesity; insulin; cytokine 
Introduction

Metabolic syndrome (MetS) is characterized by a concurrence of obesity, high levels in many CVD risk factors, and insulin resistance. The concept of MetS emerged during the 1980's and was first described in adults by Reaven [1]. However, the clustering of these cardiovascular disease risk factors occur in children as young as the age of 9 years $[2,3]$. Insulin resistance is a key component of MetS and one of the main reasons for the increase in CVD risk factors. Using HOMA as a marker of insulin resistance, healthy young adults in the upper quartile for insulin resistance with no signs of type 2 diabetes mellitus, had about 25 times increased risk of having clustered CVD risk factors compared to those in the lowest quartile [4]. The clustering also appears to be associated with sedentary lifestyle, low fitness and obesity [5,6].

Adiposity is a key component of MetS and most type 2 diabetics are obese; many believe that obesity is the main cause of insulin resistance. Hypothetically, one way adipose tissue exerts the effect on insulin resistance is through its production of cytokines. Hotamisligil et al., using an animal model, showed that presence of TNF- $\alpha$ decreased insulin sensitivity and sensitivity returned when TNF- $\alpha$ was blocked [7]. Human studies of obese adults or severe obese adolescents have shown an association between obesity and TNF- $\alpha[8,9]$. Such studies do not allow us to determine the time course for this pathophysiology. For example, insulin is an anabolic hormone and high levels of insulin increases storage of fat. Obesity and high TNF- $\alpha$ level could therefore be a result of insulin resistance instead of the cause, and finally it could be both. 
IL-6 is produced in adipose tissue and is considered a proinflammatory and immunoregulating cytokine [8]. IL-6 has been reported to be elevated in obese youth, and chronic elevation of IL-6 appears to predict the development of insulin resistance [9]. Intriguingly, IL-6 is also produced in the muscle during exercise and has been hypothesized to block the production of TNF- $\alpha$, thereby improving insulin sensitivity $[10,11]$. In studies where physiological concentrations of rhIL-6 has been administered to healthy young and elderly humans, as well as patients with type 2 diabetes, IL- 6 has been identified as a potent modulator of fat metabolism in humans, increasing lipolysis as well as fat oxidation [12]. However, there is convincing evidence that IL-6 has an important role as a proinflammatory cytokine produced by a variety of cells including leucocytes and visceral fat tissue [8]. Thus, it is likely that the effect of IL-6 may vary depending on the concentration and site of action and production.

Another inflammatory marker associated with both atherosclerotic disease and MetS is CRP [13]. CRP is produced in the liver and may be regulated by inflammatory cytokines, principally IL-6 and TNF- $\alpha$ [14]. The common link between TNF- $\alpha$, IL-6 and CRP may be obesity [9]. CRP has been known to bind to LDL cholesterol and many have reported an association between CRP levels and CHD risk [15].

The aim of the present study was to evaluate the association between CVD risk score, HOMA score, and the cytokines (CRP, IL-6 \& TNF- $\alpha$ ), fitness, and fatness in a cohort of 9-year old children. If TNF- $\alpha$ produced by abdominal fat tissue causes insulin resistance, we would expect increased levels of TNF- $\alpha$ in obese, insulin resistant children. Also, if 
muscle activation elevates IL-6, then highly fit children with low adiposity should have increased levels of IL-6, but normal levels of TNF- $\alpha$. We further included CRP in our blood analysis as a general marker of inflammation. 


\section{Methods}

All children in $3^{\text {rd }}$ grade classes (9-10 years of age) from two suburbs of Copenhagen, Denmark were invited to participate in a four-year, controlled intervention study of physical activity and health: the Copenhagen School Child Intervention Study (CoSCIS). This report uses cross-sectional data measured during the follow-up. Seven hundred and six children (69\% of the total population) volunteered at baseline and among these 613 participated at the follow-up. Complete data for all CVD risk factors were available for 434 subjects, and valid analyses of cytokines were available in 210 subjects, 113 boys and 97 girls. We decided to analyze plasma cytokines in the upper and lower quartile of a composite CVD risk factor score, because this provided sufficient statistical power. The composite risk factor score used to select the children for cytokine analysis was the sum of z-scores for the ratio of total cholesterol:HDL-C, TG, HOMA, systolic BP, skinfold, and inverse of $\mathrm{VO}_{2 \text { peak }}\left(\mathrm{ml}^{\mathrm{kg}} \mathrm{kgin}^{-1}\right)$. Since no significant differences between the two suburbs were identified for boys or girls, children from the two suburbs were analysed together. Written informed consent was obtained from the parents/guardian. The Ethical Committee of Copenhagen approved the study.

The tests were performed from September 2004 until June 2005 at all 18 schools in the communities. The blood samples were taken early in the morning in the office of the health staff after at least 8 hours fast. The exercise test was performed in a camper trailer. All other physiological tests were performed in a gym or a classroom. All tests were performed before noon $(8.00-12.00)$.

Age and anthropometry 
Age was computed from date of birth and date of examination. Stature was measured by a Harpenden stadiometer to the nearest $1 \mathrm{~mm}$ in bare stocking feet with the child standing upright against the stadiometer. Body mass was measured to the nearest $0.1 \mathrm{~kg}$ using an electronic scale (Seca 882) in the morning while the children were still fasting. Body mass index $(\mathrm{BMI})$ was calculated; mass $\bullet \operatorname{stature}^{-2}\left(\mathrm{~kg} \mathrm{~m}^{-2}\right)$. Biceps, triceps, subscapular and suprailiac skinfolds were measured in triplicate with a Harpenden skinfold calliper by the same two experienced researchers according to conventional criteria and measuring procedures, on the non-dominant side of the body. The mean of the three values was used for subsequent analysis. The thickness of the sum of four skinfolds was used as an indicator of body fatness. Waist circumference (waist) was measured with a metal anthropometric tape midway between the lower rib margin and the iliac crest, at the end of gentle expiration. Measurement was taken at right angles to the axial line of the trunk. Blood pressure Blood pressure (BP) was measured with a Dinamap XL vital signs blood pressure monitor (Critikron, Inc., Tamapa, FL) from the left arm five times in 10 minutes, with the mean of the last three measurements being recorded. Measurements were taken after the child had been lying down for 10 minutes and then sitting in upright position for five minutes with the cuff on.

Aerobic fitness measurements Aerobic fitness $\left(\mathrm{VO}_{2 \text { peak }}\right)$ was measured during a continuous, progressive, graded treadmill run using an Innovision AMIS 2001 metabolic system. The test is described in detail elsewhere [16]. The children were instructed to run until exhaustion and verbal 
encouragement was given. Standard objective criteria were used to determine if the test was performed satisfactory. The same two experienced researchers performed all tests. Blood sample Venous blood samples were taken in the morning 8:00-9:30 AM from the antecubital vein after an overnight fasting. The fast was verified. Glucose was measured immediately after sampling (Hemocue). The rest of the samples were centrifuged, the plasma aliquoted within 30 minutes, kept at $-20^{\circ} \mathrm{C}$, and later stored at $-80^{\circ} \mathrm{C}$. The stored samples were analysed at the Copenhagen Muscle Research Centre for concentrations of insulin, triglyceride (TG), HDL cholesterol (HDL-C) and total cholesterol (cholesterol). Insulin was analyzed spectrophotometrically using an enzyme linked immunosorbent assay (DAKO Insulin, Code no. K6219). Blood lipids were analyzed on a COBAS FARA (Roche, Schwitzerland) using spectrophotometry (ABX diagnostics, Montpellier, France). Cytokines were analysed with high sensitivity immunoassays. IL-6 used Quantikine High Sensitivity Enzyme-linked immunosorbent assay (ELISA), with a detection limit of $0.5 \mathrm{pg} \cdot \mathrm{ml}^{-1}$ (R\&D, Minneapolis, MN, USA). TNF- $\alpha$ used Quantikine High Sensitivity Enzyme-linked immunosorbent assay (ELISA), with a detection limit of $0.1 \mathrm{pg} \cdot \mathrm{ml}^{-1}$ (R\&D, Minneapolis, MN, USA). CRP was determined using Particleenhanced turbidimetric immunoassay: Tina-quant C-reactive protein (latex) high sensitive assay (Cobas, Roche Diagnostics GmbH, Mannheim, DEU), with a detection limit of $0.1 \mathrm{mg} \cdot 1^{-1}$.

CVD Risk factors used for clustering analysis 
We constructed two composite CVD risk score variables by summing z-scores computed "by sex". The first score included, the ratio of total cholesterol:HDL-C, TG, HOMA, systolic BP, skinfold, and inverse of $\mathrm{VO}_{2 \text { peak }}\left(\mathrm{ml} \mathrm{kg}^{-1} \mathrm{~min}^{-1}\right)$ and was only used to select blood samples for cytokine analysis. These risk factors were chosen because they are known to be major elements of the MetS. Complete data in these risk factors was obtained from 434 children. The second score only included four CVD risk factors, omitting obesity and $\mathrm{VO}_{2 \max }$, and was used as dependent variable in the analysis. The upper and lower quartile of the composite risk factor score were selected for blood analysis of cytokines $(n=210)$. This approach ensured that the analysis included some subjects who were fat, had low fitness and were insulin resistant. To avoid redundancy in the selection only one measure was selected for fatness, insulin sensitivity, cholesterol fractions, and for BP.

Data analysis

All analyses were performed using the Statistical Package for the Social Sciences (SPSS) version 16. The composite risk factor score used for the analysis included systolic BP, TG, HOMA, and cholesterol:HDL ratio. HOMA, TG, BMI, Skinfolds, waist, IL-6 and CRP were skewed and were log-transformed before z-scores (adjusted for sex) were constructed. Pearson correlation was used for bivariate associations between risk score and fitness $\left(\mathrm{VO}_{2 \text { peak }}\right)$, fatness and cytokines. General linear models were used to compare groups and were adjusted for sex and age. Logistic regression was used to predict MetS defined as a $\mathrm{z}$-score of $>1 \mathrm{SD}$ in the composite CVD risk score. 


\section{Results}

Subjects were divided into quartiles of sum of z-scores for six risk factors, and blood samples for the upper and lower quartile were analyzed for cytokine levels (total sample $=210$ ). Data for upper and lower quartile of CVD risk is presented in Table 1. Not surprisingly, the CVD risk factors used to select children for cytokine analysis were higher in the high risk group. Although cholesterol and glucose were part of the selection criteria, only small differences were found between the two groups. CRP was substantially higher in the high risk group, but,TNF- $\alpha$ and IL-6 had small and inconsistent differences and only in girls.

Insert Table 1

Bivariate associations adjusted for sex are shown in Table 2. TNF- $\alpha$ and IL-6 were not associated with any of the other variables. CRP had negative association with fitness $\left(\mathrm{VO}_{2 \text { peak }}\right)$ and consistent positive relationships to both fatness variables, HOMA, and CVD risk score (sum of z-scores of systolic BP, LnTG, total cholesterol:HDL ratio and LnHOMA). CRP correlated weakly with IL-6 ( $\mathrm{r}=0.15 ; \mathrm{p}=0.02)$, but not with TNF- $\alpha$. Fatness variables and fitness were associated with the CVD risk score. The associations between CVD risk score and fitness and fatness were stronger than between CVD risk score and CRP.

Insert Table 2

Logistic regression was used so analyze the association between CVD risk score (dichotomized at $+1 \mathrm{SD}$ ) and fitness, fatness and cytokine variables (Table 3). However, 
no children in the lowest quartile of waist (reference group) had MetS, and for BMI and skinfold there was only one child with MetS. Thus, we omitted the logistic regression for fitness and fatness variables and replace it with a crosstab table. In the reference group (highest quartile) of fitness there were two children with MetS (Table 3). TNF- $\alpha$ and IL-6 showed no association with CVD risk score, but the upper quartile of CRP had an 11 times increased risk for high CVD risk score compared to the lowest quartile. Because IL-6 is produced in the muscle and has been hypothesized to block the production of TNF- $\alpha$, we also analyzed ratio IL-6/ TNF- $\alpha$, but this did not improve associations (results not shown).

Insert table 3 


\section{Discussion}

The present study included two groups of $3^{\text {rd }}$ grade children $(\sim 9$ years old $)$ selected according to their CVD risk factor profile. The sample included children with a wide range of characteristics, some who were obese, had clustered CVD risk, or low fitness, but not necessarily all traits in the same child. All fatness variables (independent of cytokines) and low physical fitness ( $\mathrm{VO}_{2}$ peak) predicted clustering of the CVD risk factors and HOMA. TNF- $\alpha$ and IL-6, however, were not related to clustered risk or HOMA. This suggests that in children the influence of fatness and low fitness levels on MetS and insulin resistance precedes any effect of cytokines.

We found no association between any of the risk factors and TNF- $\alpha$ and IL- 6 , but CRP was related to all CVD risk factors, fitness, and fatness. It is important for prevention to understand how clustering of CVD risk factors develops in children and in these apparently healthy children TNF- $\alpha$ and IL-6 appears to have no major role in the early development. In theory, if TNF- $\alpha$ causes insulin resistance, then increased levels of TNF$\alpha$ should be present in obese, insulin resistant children. Simultaneously, if muscle activation elevates IL-6, then highly fit children (high $\mathrm{VO}_{2 \text { peak }}$ ) with low adiposity should have increased levels of IL-6, but normal levels of TNF- $\alpha$. Our results would not support these assertions for children.

CRP has been found to be consistently associated with atherosclerosis [15]. Intriguingly, atherosclerosis could cause increased CRP level through release of cytokines, but in these young children, where atherosclerosis has not progressed, it is more likely that elevated 
CRP concentrations precedes any impairment of endothelial function and promote intima media thickening [14]. Although our results would support the fact that CRP elevates before the cytokines, we cannot verify this relationship because we do not have any direct measures of atherosclerosis.

IL-6 levels were found to correlate with CRP, which is consistent with the fact that IL-6 is a major inducer of CRP production. Despite this, only CRP showed consistent associations with clustering of risk, while IL-6 and TNF appeared unrelated to these parameters. Our findings may be influenced by the fact that both IL-6, and in particular TNF- $\alpha$, are very sensitive markers, with short half lives and present only at very low concentrations in healthy children. Moreover, biologically significant alterations in the levels of both cytokines in the microenvironment cannot be fully excluded based on measurements in peripheral blood. However, these data do not support the notion that TNF- $\alpha$ and IL- 6 play a primary role in the induction of the processes that lead to clustering of risk factors and insulin resistance, nor do the data support that IL-6 produced by muscle tissue has paracrine effects on TNF- $\alpha$ production.

Elevated levels of TNF- $\alpha$, IL- 6 and CRP have been found in obese adults and adolescents who had decreased insulin sensitivity $[8,9,17-20]$. Rubin et al. showed in a crosssectional study that TNF- $\alpha$, but not IL-6, associated with insulin resistance [19]. When regression models included weight status, the significance of TNF- $\alpha$ to insulin resistance disappeared. This does not mean that TNF- $\alpha$ could not be one of the causes of insulin resistance, it just suggests that TNF- $\alpha$ and BMI are co-variates. In our young children we 
found associations between insulin resistance and obesity, very low levels of TNF- $\alpha$, and no association between TNF- $\alpha$ and either of the two. The source of some of the TNF- $\alpha$ is the adipose tissue [7] and since the variations in TNF- $\alpha$ were low, but the variations in adiposity were large, the associations between CVD risk score and adiposity probably eclipsed the associations with TNF- $\alpha$. Thus, we found no support for TNF- $\alpha$ as causal factor for insulin resistance in our children. Rubin et al's subjects were adolescents, which may have given more time for associations to develop. It may be that leptin and adiponectin, both secreted by the fat cell, are the causes and the cytokines are modifiers [21]. Changes in these two adipokines may precede the changes in the cytokines. We know leptin is already elevated in obese children and is associated with insulin resistance [22], and adiponectin is suppressed [19].

Previously, we observed clustering of CVD risk factors in children this age [2,3] and similar results were found in this cohort (analysis not reported). Therefore the clustering of risk factors appears to occur before high levels of inflammatory markers are present. The clustering of CVD risk factors could have multiple causes, independent of inflammation. The increase in these cytokines may be secondary to CVD clustering. Further studies should attempt to characterize the role of anti-inflammatory mediators, including soluble TNF- $\alpha$ receptors and interleukin-1 receptor antagonist, at this early stage of the pathogenesis, because these influence the inflammatory activity. Moreover, the potential impact of immune response gene polymorphisms should be evaluated, since these may influence not only the rate of cytokine release, but also receptor sensitivity. 
The strength of the present study is the availability of a number of fatness parameters, direct measurement of $\mathrm{VO}_{2 \text { peak }}$, the traditional CVD risk factors and TNF- $\alpha$, IL- 6 and $\mathrm{CRP}$ in a young cohort, where insulin resistance, obesity and atherosclerosis have not progressed. This may allow a further dissection to determine the rank order in which the different stages of the metabolic syndrome develop. A weakness of the study is the crosssectional nature, but the study will be continued, where we hopefully can measure whether cytokine levels increase over time in the subjects who were insulin resistant or had clustered risk, but where cytokine levels were low at the age of 9 years.

In conclusion, the data of the present study do not support the notion that TNF- $\alpha$ release is associated with low insulin sensitivity or clustering of CVD risk factors in this young cohort. There were signs of inflammation on fat and low fit individuals based on the association with CRP levels. The results suggest that the associations of fitness and fatness variables with HOMA and clustered risk may be caused by other mechanisms related to these exposures. The role of IL-6 was unclear in the present cohort.

\section{Acknowledgments}

The authors wish to thank Copenhagen Muscle Research Centre for analyzing blood lipids and insulin. This work was supported by grants from the Danish Heart Foundation, The National Board of Health, The Danish Ministry of Health, The Danish Ministry of Culture and The Danish Sport Association. 
1. Reaven GM. Role of insulin resistance in human disease (syndrome X): an expanded definition. Annu Rev Med 1993; 44: 121-31.

2. Andersen LB, Wedderkopp N, Hansen HS, Cooper AR, Froberg K. Biological cardiovascular risk factors cluster in Danish children and adolescents. Danish part of the European Heart Study. Prev Med 2003; 37: 363-7.

3. Andersen LB, Harro M, Sardinha LB, Froberg K, Ekelund U, Brage S et al. Physical activity and clustered cardiovascular risk in children: a cross-sectional study (The European Youth Heart Study). Lancet 2006; 368: 299-304.

4. Andersen LB, Boreham CA, Young IS, Davey SG, Gallagher AM, Murray L et al. Insulin sensitivity and clustering of coronary heart disease risk factors in young adults. The Northern Ireland Young Hearts Study. Prev Med 2006; 42: 73-7.

5. Anderssen SA, Cooper AR, Riddoch C, Sardinha LB, Harro M, Brage S et al. Low cardiorespiratory fitness is a strong predictor for clustering of cardiovascular disease risk factors in children independent of country, age and sex. Eur J Cardiovasc Prev Rehabil 2007; 14: 526-31.

6. Andersen LB, Sardinha LB, Froberg K, Riddoch CJ, Page AS, Anderssen SA. Fitness, fatness and clustering of cardiovascular risk factors in children from 
Denmark, Estonia and Portugal: the European Youth Heart Study. Int J Pediatr Obes 2008; 3 Suppl 1: 58-66.

7. Hotamisligil GS, Shargill NS, Spiegelman BM. Adipose expression of tumor necrosis factor-alpha: direct role in obesity-linked insulin resistance. Science 1993; 259: 87-91.

8. Kern PA, Ranganathan S, Li C, Wood L, Ranganathan G. Adipose tissue tumor necrosis factor and interleukin-6 expression in human obesity and insulin resistance. Am J Physiol Endocrinol Metab 2001; 280: E745-E751.

9. Balagopal P, George D, Patton N, Yarandi H, Roberts WL, Bayne E et al. Lifestyleonly intervention attenuates the inflammatory state associated with obesity: a randomized controlled study in adolescents. J Pediatr 2005; 146: 342-8.

10. Pedersen BK, Toft AD. Effects of exercise on lymphocytes and cytokines. Br J Sports Med 2000; 34: 246-51.

11. Pedersen BK, Steensberg A, Fischer C, Keller C, Keller P, Plomgaard P et al. Searching for the exercise factor: is IL-6 a candidate? J Muscle Res Cell Motil 2003; 24: 113-9. 
12. van HG, Steensberg A, Sacchetti M, Fischer C, Keller C, Schjerling P et al. Interleukin-6 stimulates lipolysis and fat oxidation in humans. J Clin Endocrinol Metab 2003; 88: 3005-10.

13. Festa A, D'Agostino R, Jr., Howard G, Mykkanen L, Tracy RP, Haffner SM. Chronic subclinical inflammation as part of the insulin resistance syndrome: the Insulin Resistance Atherosclerosis Study (IRAS). Circulation 2000; 102: 42-7.

14. Steinberger J. Modest lifestyle intervention attenuates the inflammatory state in children. J Pediatr 2005; 146: 308-9.

15. Casas JP, Shah T, Hingorani AD, Danesh J, Pepys MB. C-reactive protein and coronary heart disease: a critical review. J Intern Med 2008; 264: 295-314.

16. Eiberg S, Hasselstrom H, Gronfeldt V, Froberg K, Svensson J, Andersen LB. Maximum oxygen uptake and objectively measured physical activity in Danish children 6-7 years of age: the Copenhagen school child intervention study. Br J Sports Med 2005; 39: 725-30.

17. Pannacciulli N, Cantatore FP, Minenna A, Bellacicco M, Giorgino R, De PG. Creactive protein is independently associated with total body fat, central fat, and insulin resistance in adult women. Int J Obes Relat Metab Disord 2001; 25: 141620. 
18. Straczkowski M, Kowalska I, Dzienis-Straczkowska S, Stepien A, Skibinska E, Szelachowska $\mathrm{M}$ et al. Changes in tumor necrosis factor-alpha system and insulin sensitivity during an exercise training program in obese women with normal and impaired glucose tolerance. Eur J Endocrinol 2001; 145: 273-80.

19. Rubin DA, McMurray RG, Harrell JS, Hackney AC, Thorpe DE, Haqq AM. The association between insulin resistance and cytokines in adolescents: the role of weight status and exercise. Metabolism 2008; 57: 683-90.

20. Nassis GP, Papantakou K, Skenderi K, Triandafillopoulou M, Kavouras SA, Yannakoulia $\mathrm{M}$ et al. Aerobic exercise training improves insulin sensitivity without changes in body weight, body fat, adiponectin, and inflammatory markers in overweight and obese girls. Metabolism 2005; 54: 1472-9.

21. McMurray RG, Hackney AC. Endocrine responses to exercise and training. In:Garrett WG, Kirkendall DT. Sports Medicine, vol 1. 2000; 135-62. Baltimore, Williams \& Wilkins.

22. Cohen B, Novick D, Rubinstein M. Modulation of insulin activities by leptin. Science 1996; $274:$ 1185-8. 
Table 1. Mean and standard deviation (SD) for key variables in the high and low risk groups (upper and lower quartiles of composite risk score) for boys and girls.

\begin{tabular}{|c|c|c|c|c|c|c|c|c|c|c|}
\hline & \multicolumn{4}{|c|}{ Boys $(\mathrm{N}=113)$} & \multicolumn{4}{|c|}{ Girls $(\mathrm{N}=97)$} & \multirow{3}{*}{$\begin{array}{c}\text { P-value } \\
\text { Low vs High }\end{array}$} & \multirow{3}{*}{$\begin{array}{l}\text { P-value } \\
\text { Sex }\end{array}$} \\
\hline & \multicolumn{2}{|c|}{$\begin{array}{l}\text { Low Risk } \\
\qquad(\mathrm{n}=\end{array}$} & \multicolumn{2}{|c|}{$\begin{array}{l}\text { High Risk } \\
\qquad(\mathrm{n}=\end{array}$} & \multicolumn{2}{|c|}{$\begin{array}{l}\text { Low Risk } \\
\qquad(\mathrm{n}=\end{array}$} & \multicolumn{2}{|c|}{$\begin{array}{l}\text { High Risk } \\
\qquad(\mathrm{n}=)\end{array}$} & & \\
\hline & Mean & $\mathrm{SD}$ & Mean & $\mathrm{SD}$ & Mean & SD & Mean & $\mathrm{SD}$ & & \\
\hline Age (years & 9.39 & 1.44 & 9.38 & 1.66 & 9.46 & 0.35 & 9.42 & 1.09 & NS & NS \\
\hline Stature $(\mathrm{cm})$ & 138.8 & 5.5 & 143.8 & 6.4 & 136.1 & 5.4 & 140.9 & 6.4 & $* * *$ & $* * *$ \\
\hline Body Mass (kg) & 30.2 & 3.5 & 41.7 & 8.0 & 27.9 & 2.9 & 37.7 & 6.5 & $* * *$ & $* * *$ \\
\hline $\mathrm{BMI}\left(\mathrm{kg} \mathrm{m}^{2}\right)$ & 15.63 & 1.12 & 20.08 & 2.98 & 15.06 & 1.32 & 18.92 & 2.51 & $* * *$ & $* *$ \\
\hline Waist $(\mathrm{cm})$ & 58.3 & 3.2 & 70.7 & 8.5 & 56.1 & 2.9 & 66.5 & 7.6 & $* * *$ & $* * *$ \\
\hline Skinfold (mm) & 5.43 & 1.23 & 11.70 & 5.42 & 5.91 & 1.36 & 11.84 & 4.78 & $* * *$ & * \\
\hline $\mathrm{VO}_{2 \text { peak }}\left(\mathrm{ml} \cdot \mathrm{min}^{-1} \mathrm{~kg}^{-1}\right) \#$ & 56.4 & 5.3 & 45.9 & 5.8 & 51.5 & 4.8 & 43.6 & 6.5 & $* * *$ & \\
\hline Glucose (mM/1)\#\# & 4.84 & 0.51 & 4.81 & 0.47 & 4.65 & 0.45 & 4.89 & 0.58 & Girls * & $\mathrm{N}$ \\
\hline Insulin (mU/l) & 3.75 & 1.50 & 9.00 & 6.21 & 4.00 & 1.54 & 8.85 & 4.28 & $* * *$ & $\mathrm{~N}$ \\
\hline HOMA & .81 & .35 & 1.90 & 1.28 & .82 & .32 & 1.97 & 1.20 & $* * *$ & NS \\
\hline Total cholesterol (mmol/1) & 3.78 & 0.51 & 3.99 & 0.59 & 3.92 & 0.64 & 4.14 & 0.62 & $*$ & \\
\hline HDL-C (mmol/l) & 1.76 & 0.32 & 1.40 & 0.30 & 1.76 & 0.43 & 1.37 & 0.34 & $* * *$ & $\mathrm{~N}$ \\
\hline Triglyceride (mmol/l) & 0.37 & 0.11 & 0.75 & 0.37 & 0.42 & 0.14 & 0.77 & 0.29 & $* * *$ & $\mathrm{~N}$ \\
\hline Diastolic BP (mmHg) & 61 & 6 & 67 & 7 & 58 & 7 & 65 & 6 & $* * *$ & \\
\hline Systolic BP (mmHg) & 101 & 7 & 112 & 11 & 95 & 6 & 108 & 9 & $* * *$ & $* *$ \\
\hline $\mathrm{CRP}(\mathrm{mg} / \mathrm{l})$ & 0.43 & 0.69 & 0.77 & 0.74 & 0.37 & 0.25 & 1.28 & 1.82 & $* * *$ & $\mathrm{~N}$ \\
\hline TNF (pg/ml)\#\# & 15.48 & 10.33 & 12.05 & 11.15 & 8.82 & 9.08 & 12.47 & 9.33 & Girls. $\mathrm{P}=0.06$ & $\mathrm{~N}$ \\
\hline IL-6 (pg/ml)\#\# & 1.3 & 1.4 & 1.0 & 1.7 & 1.0 & 1.1 & 1.8 & 2.1 & Girls * & NS \\
\hline
\end{tabular}

$\mathrm{P}<0.05^{*} ; \mathrm{p}<0.01 * * ; \mathrm{p}<0.001 * * * ; \#$ interaction (sex by risk group); \#\# interaction between sex and risk group, difference only for girls.

\section{Interaction and difference between groups were tested with GLM analysis.}


Table 2. Pearson correlations between CVD risk z-score (BPsys $+\ln$ TG+Chol:HDL ratio+lnHOMA), cytokines, HOMA, fatness, and fitness $\left(\mathrm{VO}_{2 \text { peak }}\right)$ variables. All associations are adjusted for sex.

\section{LnSkinfold LnWaist LnBMI Fitness TNF- $\alpha$ IL-6 CRP Ln-HOMA LnZ-score}

LnSkinfold $\quad 1.00$

\begin{tabular}{|c|c|c|c|c|c|c|c|c|}
\hline LnWaist & $0.88 * *$ & 1.00 & & & & & & \\
\hline LnBMI & $0.90 * *$ & $0.90 * *$ & 1.00 & & & & & \\
\hline Fitness & $-0.75^{* *}$ & $-0.67 * *$ & $-0.69 * *$ & * 1.00 & & & & \\
\hline TNF- $\alpha$ & -0.02 & 0.00 & -0.01 & 0.09 & 1.00 & & & \\
\hline IL-6 & 0.06 & 0.04 & 0.05 & -0.04 & -0.02 & 1.00 & & \\
\hline CRP & $0.52^{* *}$ & $0.47 * *$ & $0.51^{* *}$ & $-0.49 * *$ & -0.08 & 0.15* 1.00 & & \\
\hline LnHOMA & $0.61^{* *}$ & $0.59 * *$ & $0.63^{* *}$ & $-0.49 * *$ & 0.02 & $0.01 \quad 0.35^{* *}$ & 1.00 & \\
\hline LnZ-score & $0.66 * *$ & $0.68 * *$ & $0.68 * *$ & $-0.55^{* *}$ & 0.00 & $0.06 \quad \mathbf{0 . 3 4} * *$ & $0.66 * *$ & 1.00 \\
\hline
\end{tabular}

$* \mathrm{p}<0.01 ; * * \mathrm{p}<0.001$ 
Table 3. Odds ratios for having $+1 \mathrm{SD}$ in sum of CVD risk z-score (BPsys $+\ln$ TG+Chol:HDL ratio+lnHOMA) between quartiles of TNF- $\alpha$, IL- 6 and CRP. Reference groups were lowest groups. All variables were computed 'by sex'. Analyses for fitness and fatness variables are presented as number of cases in each quartile, because the sample was inadequate to perform logistic regression.

$\begin{array}{cccccccc}\text { Total N=207 } & \text { TNF- } \alpha & \text { IL-6 } & \text { CRP } & \text { fitness } & \text { BMI } & \text { Waist } & \text { Skinfold } \\ \text { CVD Risk Score } & \text { OR }(95 \% \text { CI }) & \text { OR }(95 \% \text { CI }) & \text { OR }(95 \% \text { CI }) & \text { cases } & \text { cases } & \text { cases } & \text { cases } \\ 1^{\text {st }} \text { QT } & 1 & 1 & 1 & 20 & 1 & 0 & 1 \\ 2^{\text {nd }} \text { QT } & 0.9(0.3-2.7) & 1.1(0.4-3.3) & 2.2(0.4-12.4) & 6 & 2 & 3 & 1 \\ 3^{\text {rd }} \text { QT } & 0.8(0.3-2.7) & 1.3(0.5-3.6) & 5.8(1.2-27.9) & 4 & 5 & 5 & 6 \\ 4^{\text {th }} \text { QT } & 1.1(0.4-3.2) & 0.6(0.2-1.9) & 11.3(2.5-52.4) & 2^{*} & 24 & 24 & 24\end{array}$

